Jurnal Pendidikan Anak Usia Dini

ISSN 2301-9905

Volume 10, No. 1, Juli 2019

Fakultas Keguruan dan Ilmu Pendidikan- Universitas Muhammadiyah Tangerang

\title{
Pemerolehan Kosa Kata Bahasa Inggris Dasar Oleh Individu Autis Melalui Media Interaktif
}

\author{
Diah Retno Anggraini ${ }^{1}$, Titi Rachmi ${ }^{2}$, Nargis ${ }^{3}$ \\ 1,3Program Studi Pendidikan Bahasa Inggris, 2Program Studi Pendidikan Guru \\ Pendidikan Anak Usia Dini,; Fakultas Keguruan Dan Ilmu Pendidikan;Universitas \\ Muhammadiyah Tangerang

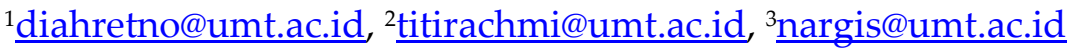

\begin{abstract}
Abstrak
Keterbatasan dan kesulitan pemerolehan bahasa oleh individu autis adalah masalah utama bagi orang tua dan praktisi serta akademisi pendidikan. Metode dan teknik pengajaran dan pembelajaran dikembangkan dan dimodifikasi sehingga kemampuan mereka untuk merespons dan berbahasa meningkat. Indikator perkembangan individu autis dilihat dari perkembangan kemampuan merespon dan berbicara, hal itu dapat didukung oleh media interaktif talking photo. Talking photo adalah media interaktif yang dapat menyimpan dan menghasilkan suara. Media ini dapat mendukung pengajaran untuk memperkenalkan kosakata bahasa Inggris dasar kepada individu autisme. Kosakata bahasa Inggris dasar dalam penelitian ini adalah anggota tubuh dan aktivitas yang biasa individu autis lakukan. Penelitian ini dilakukan dengan metode kualitatif dengan mendeskripsikan penerapan talking photo dalam pemerolehan kosa kata Bahasa Inggris Dasar kepada individu dengan autisme. 5 individu autis pra-sekolah dilibatkan dalam penelitian ini, mereka dipaparkan secara intensif selama satu bulan 10 kosakata bahasa Inggris dasar tentang anggota tubuh dan kegiatan sehari-hari. Hasil yang diperoleh, dari masing-masing dari 10 kosakata, rata-rata 5 kosakata yang mereka dapat melafalkan baik itu anggota tubuh dan aktifitas sehari -hari. Perkembangan kemajuan individu autistik terjadi karena integrasi stimulus dan dukungan keluarga dan praktisi pendidikan, serta media sebagai sarana mempercepat pencapaian kemajuan.
\end{abstract}

Kata Kunci: Individu autis, Bahasa Inggris Dasar, Media Interaktif

\begin{abstract}
The limitations and difficulties of language acquisition by autistic individuals are a major problem for parents and practitioners as well as educational academics. Teaching and learning methods and techniques are developed and modified so that their ability to respond and their language increases. Indicator of the progress of autistic individuals seen from the development of the ability to respond and speak, it can be supported by talking photo. Talking photo is an interactive media that can store and produce sound. This media can
\end{abstract}


Jurnal Pendidikan Anak Usia Dini

ISSN 2301-9905

Volume 10, No. 1, Juli 2019

Fakultas Keguruan dan Ilmu Pendidikan- Universitas Muhammadiyah Tangerang

support teaching to introduce English vocabulary to individuals with autism. English vocabularies in this study are parts of body and activities. This research was conducted with a qualitative method to describe the application of talking photos in teaching Basic English vocabulary to individuals with autism. 5 pre-school autistic individuals were included in this study with intensive teaching for one month. Every autistic individual is exposed to 10 English vocabularies intensively about activities and part of body. The results obtained, from each of the 10 vocabulary words, averaged 5 vocabulary words that they could recite both activities and part of body and 5 vocabulary words that they could respond correctly, both activities and parts of body. The development of autistic individual progress occurs because of the integration of stimulus and family support and education practitioners, and the media as a means of accelerating the achievement of progress.

Keywords: Individual Autism, Basic English, Interactive Media

\section{Pengantar}

Pendidikan adalah salah satu hal yang sangat penting untuk membangun sebuah negara menjadi lebih baik. Peran pendidikan harus disejajarkan pada tuntutan internasional dalam era globalisasi seperti saat ini. Bahasa Inggris merupakan bahasa internasional yang saat ini menjadi bahasa kedua dan kedudukannya sama penting dengan Bahasa Indonesia. Melihat kondisi tersebut, para praktisi pendidikan di tingkat usia dini sudah mulai memasukkan Bahasa Inggris ke dalam program pembelajaran mereka.

Individu autis merupakan individu dengan keterbatasan,baik itu bahasa dan kemampuan merespon. Keterbatasan yang dialami oleh individu autis, tidak menjadi alasan bagi mereka untuk memperoleh pendidikan, karena UndangUndang Republik Indonesia mengatakan bahwa setiap warga negara berhak mendapatkan pendidikan tanpa terkecuali.

Keterbatasan kemampuan yang dimiliki individu autis menyebabkan kesulitan dalam mengajarkan Bahasa Inggris. Bahasa Inggris di negara kita Indonesia menjadi bahasa kedua setelah Bahasa Indonesia. Hal inilah yang mengusik para praktisi pendidikan dan orangtua untuk turut memperkenalkan Bahasa Inggris kepada individu autis, tetapi pada kenyataannya itu bukanlah hal yang mudah. 
Jurnal Pendidikan Anak Usia Dini

ISSN 2301-9905

Volume 10, No. 1, Juli 2019

Fakultas Keguruan dan Ilmu Pendidikan- Universitas Muhammadiyah Tangerang

Media interaktif merupakan media untuk merangsang respon penggunanya.

Media interaktif biasa digunakan dalam proses belajar mengajar, yang tujuannya agar suasana pembelajaran lebih "hidup" sehingga terjadi komunikasi dua arah. Media interaktif yang digunakan dalam penelitian ini adalah talking photo. Talking photo adalah media yang dapat mengeluarkan suara dengan didukung oleh gambar, potongan sketsa gambar serta boneka sebagai media interaktif digunakan untuk membantu proses pembelajaran, sehingga penyampaian dapat berjalan dengan menyenangkan dan individu autis berada dalam kondisi sedang bermain.

Talking photo dapat mengeluarkan suara, suara yang dihasilkan bisa berasal dari suara rekaman atau suara orangtua dan praktisi pendidikan. Suara tersebut dapat dimodifikasi dan disesuaikan dengan kebutuhan dan kondisi individu autis. Setiap suara yang yang dibuat dan direkam, dapat diperbaharui setiap saat dan proses pembaharuan dapat dilakukan dengan mudah, sehingga praktisi pendidikan dan orangtua dapat menggunakannya tanpa bantuan ahli. Selain itu, dalam penerapamya dapat diikuti dengan potongan-potongan sketsa gambar atau boneka, yang tentu saja menarik bagi individu autis.

Kosakata merupakan hal mendasar yang harus dikuasai bagi para siswa pembelajar Bahasa Inggris. Kosakata mulai diperkenalkan kepada individu autis sedini mungkin, sejak usia prasekolah. Kosakata yang diperkenalkan adalah kosakata dasar terkait anggota tubuh dan aktifitas sehari-hari yang biasa individu autis lakukan.

Berdasarkan pemaparan latar belakang diatas, maka penelitian ini akan memaparkan penerapan media interaktif, yaitu talking photo dalam proses pemerolehan kosakata Bahasa Inggris dasar tentang anggota tubuh dan aktifitas pada individu autis.

\section{Metode Penelitian}




\section{"Ceria”}

Jurnal Pendidikan Anak Usia Dini

ISSN 2301-9905

Volume 10, No. 1, Juli 2019

Fakultas Keguruan dan Ilmu Pendidikan- Universitas Muhammadiyah Tangerang

Penelitian ini menggunakan teknik kualitatif dengan mendeskripsikan penerapan media interaktif berupa talking photo dalam memperkenalkan kosakata bahasa Inggris dasar tentang anggota tubuh dan aktifitas. Penelitian ini mengikutsertakan 5 individu autis sebagai responden, dan peneliti sebagai participant observer. Dalam pengajaran dan pengaplikasian media interaktif talking photo dilakukan oleh guru, hal ini karena pertimbangan kondusif dan terbiasa., tetapi sebelumnya guru diberi pengarahan tentang pengaplikasian dan worksheet serta evaluasi yang harus dilakukan untuk melihat progress pembelajaran. Responden dipaparkan secara intensive selama satu bulan 10 kosakata anggota tubuh dan 10 kosakata terkait aktifitas. Di akhir perlakuan, individu autis akan dilihat progress melalui tes. Tes yang diberikan terdapat dalam beberapa bentuk, yaitu mengisi worksheet yang dilengkapi gambar dan merespon.

\section{Hasil dan Pembahasan}

Pemaparan secara intensif selama satu bulan tentang 10 kosakata anggota tubuh dan 10 tentang kosakata aktifitas sehari-hari, menggunakan, diperoleh rata-rata responden dapat menyebutkan 5 kosakata terkait anggota tubuh, yaitu mata-eye, telinga-ear, hidung-nose, tangan-hand dan kaki-leg serta 5 kosakata aktifitas seharihari, seperti makan-eat, berdoa-pray, jalan-walk, bermain-play, membaca-read, meskipun dalam pelafalan tidak sebagus individu normal.

Mereka cenderung bisa mengucapkan kosakata yang memiliki bunyi 2-3 huruf. Hal ini terjadi karena adanya gangguan bagian otak pada individu autis, sehingga individu autis sulit merespon terhadap informasi sensoris yang mereka terima, seperti suara-suara. Seperti yang diungkapkan oleh Lombardo dan Cuesta dalam BBC,(2009) pada individu normal bagian dari otak yang disebut dengan ventrodial pre-frontal cortex (vMPFC) aktif bekerja disaat berpikir, tetapi pada individu autis tidak aktif bekerja. Akibatnya otak individu autis harus bekerja keras 
Jurnal Pendidikan Anak Usia Dini

ISSN 2301-9905

Volume 10, No. 1, Juli 2019

Fakultas Keguruan dan Ilmu Pendidikan- Universitas Muhammadiyah Tangerang

dalam memproses informasi dan mengeluarkan output. Hal inilah yang menyebabkan individu autis tidak maksimal dalam berbahasa dan komunikasi.

Komunikasi merupakan proses individu bertukar informasi dan menyampaikan pikirannya, dimana ada pengirim pesan yang mengkodekan pesan dan penerima mendekodekan pesan/memahami pesan. (Bernstein \& Tiegerman, 2003). Proses komunikasi terjadi melalui bahasa. Bentuk bahasa dapat berupa isyarat/gestur, tulisan, gambar, simbol atau wicara. Dalam proses komunikasi, komunikan dan komunikator menjalin hubungan yang saling memahami bahasa yang digunakan sebagai alat penyampai pesan. Seperti yang dilakukan individu autis dengan orangtua dan guru atau caregiver. Individu memukul kepala mereka sendiri sebagai tanda meminta sesuatu, orangtua dan caregiver serta guru melarangnya dengan cara menggerakkan telapak tangan ke kanan ke kiri sebagai tanda tidak menyetujuinya. Ilustrasi di atas menunjukkan adanya proses komunikasi secara efektif dimana ibu, caregiver atau guru dapat memahami pesan yang disampaikan individu autis dan individu autis memahami isyarat tangan yang bergerak sebagai tanda permintaannya tidak disetujui.

Anak autisme memiliki kesulitan memahami dan menggunakan bahasa dalam berkomunikasi dengan orang lain. Kesulitan berkomunikasi anak autisme dalam menggunakan bahasa menyangkut dua aspek yakni aspek receptive language (bahasa reseptif) dan expresive language (bahasa ekpresif) (Bernstein \& Tiegerman, 2003). Bahasa reseptif merupakan kemampuan anak dalam mendengar dan memahami bahasa. Sedang bahasa ekspresif merupakan kemampuan anak untuk menggunakan bahasa baik verbal, tulisan maupun gestur. Sebagai contoh kesulitan anak autisme dalam memahami komunikasi menggunakan bahasa lisan dalam aspek bahasa reseptif, nampak ketika seseorang meminta kepada individu autisme untuk melakukan sesuatu, misalnya "sentuh telinga kanan!". Individu autisme kesulitan untuk melakukan perintah tersebut dengan tepat karena ia memiliki kesulitan untuk memahami konsep kata sentuh, telinga dan kanan. 


\section{"Ceria”}

Jurnal Pendidikan Anak Usia Dini

ISSN 2301-9905

Volume 10, No. 1, Juli 2019

Fakultas Keguruan dan Ilmu Pendidikan- Universitas Muhammadiyah Tangerang

Apalagi konsep kata tersebut disusun menjadi kalimat perintah yang lebih rumit.

Sedang kesulitan anak autisme dalam berkomunikasi menggunakan bahasa dalam aspek bahasa ekspresif, nampak ketika anak autisme menginginkan sesuatu, misalnya ketika ingin minum air. Anak autisme cenderung mondar-mandir, diam saja atau bahkan hanya menangis. Anak autisme tersebut memiliki kesulitan untuk mengungkapkan keinginannya kepada orang lain.

Dardjowidjojo (2005: 225 dalam Tanjung \& Siregar, 2000) mengemukakan bahwa pemerolehan bahasa atau akuisi bahasa (language acquisition), yaitu proses penguasaan bahasa yang dilakukan oleh anak secara natural pada waktu dia belajar bahasa ibu (native language). Proses penguasaan bahasa yang oleh anak dilakukan secara natural. Proses penguasaan bahasa dilakukan dengan cara anak belajar bahasa yang digunakan oleh orang dewasa dalam masa memperoleh bahasa ibu. Pemerolehan bahasa ibu tergantung lingkungan anak. Penguasaaan bahasa secara tidak disadari atau informal diperoleh dengan cara menggunakan bahasa itu dalam berkomunikasi.

Talking Photo adalah salah satu penerapan media interaktif. Manfaat praktisi pendidikan dan orangtua menggunakan talking photo sebagai media interaktif pembelajaran, karena talking photo dapat menggabungkan narasi atau cerita bergambar dengan suara praktisi pendidikan atau orangtua sendiri dan dapat disesuaikan dengan capaian pembelajaran pada saat itu, serta dapat dirubah dan dihapus sesuai dengan kebutuhan dan kondisi individu autis. Prinsip Talking photo ini mendukung komunikasi intensional yang diterapkan pada individu autis, yaitu penyampaian pesan dengan gesture (gerak bahasa tubuh) yang mengkombinasikan koordinasi perhatian ke objek atau orang lain, gerak bahasa tubuh yang disepakati bersama, serta penggunan kata (Jordan \& Powell, 2002) seperti meminta agar memberikan sebuah objek yang diinginkan, melakukan sesuatu, dan tindakan serta memberikan objek yang ada di tangan dengan menjulurkannya pada orang lain yang memintanya setidaknya separuh dari jarak antara individu autis dan orang 


\section{"Ceria”}

Jurnal Pendidikan Anak Usia Dini

ISSN 2301-9905

Volume 10, No. 1, Juli 2019

Fakultas Keguruan dan Ilmu Pendidikan- Universitas Muhammadiyah Tangerang

tersebut. Hal ini dilakukan untuk mendapatkan perhatian bersama, yaitu perilaku komunikasi terarah mengenai objek dan berusaha agar orang lain berkomentar, tertawa, tersenyum, menunjukkan perhatian, atau memberi label. Hal tersebut dapat berjalan dengan baik melalui talking photo. Talking photo dapat menciptakan komuikasi dan kolaborasi antara individu autis dan orangtua, karena pengguna dibiarkan bebas untuk berekspresi menggunakan photo saat melakukan aktivitas sehari-hari, maupun gambar yang diperoleh dari internet, dan menambahkan suara untuk mendukung cerita yang dibuat.

Selain itu dengan talking photo kemampuan merespon individu autis meningkat, karena di sertai gambar dan suara yang membuat individu autis tetap berkonsentrasi. Aarons dan Gittents, 1992, Lovaas, 1981, Nakita, 2002, Jordan \& Powell, 2002, Berntein \& Tiegerman, 2003, menyatakan bahwa individu autis hanya fokus terhadap hal-hal tertentu, sehingga mereka seolah-olah memiliki dunia mereka sendiri. Hal inilah yang dimanfaatkan oleh peneliti dengan memakai gambar yang dilengkapi suara yang mereka suka sehingga individu autis tetap fokus, pada akhirnya proses pembelajaran berprogres baik.

\section{Kesimpulan dan Saran}

Selama satu bulan pemaparan intensif, rata-rata 5 kosakata anggota tubuh dan 5 kosakata aktifitas sehari-hari dapat responden ucapkan dan respon dalam bentuk menunjuk gambar yang sesuai. Rata-rata dari mereka dapat mengucapkan kata yang jika diucapkan berbunyi 2-3 huruf. Hal ini dikarenakan intensitas pengulangan kata tersebut, baik itu di rumah, sekolah, atau media yang biasa mereka tonton. Memori mereka menyerap dan menyimpannya, sehingga mereka dapat merespon berdasarkan bunyi kata yang telah mereka kenal sebelumnya.

Pemerolehan kosakata dasar bagi individu autis bisa meningkat dan mengalami progress jika selalu dilatih setiap hari. Individu normal saja butuh waktu untuk mengucapkan dan merespon kosakata Bahasa Inggris, apalagi 


\section{"Ceria”}

Jurnal Pendidikan Anak Usia Dini

ISSN 2301-9905

Volume 10, No. 1, Juli 2019

Fakultas Keguruan dan Ilmu Pendidikan- Universitas Muhammadiyah Tangerang

individu autis itu sendiri. Selain itu ketekunan orangtua dan sinergi antara praktisi pendidikan yaitu guru atau caregiver menjadi indicator kemajuan progress individu autis serta lingkungan tempat individu tersebut berada.

Pengakuan

Artikel ini ditulis sebagai kontribusi dan penghargaan dari penulis untuk Ristekdikti atas bantuan dana penelitian.

\section{Daftar Acuan}

Alwasilah, A.C., Pokoknya Kualitatif Dasar-Dasar Merancang dan Melakukan Penelitian Kualitatif. Bandung : Pustaka Jaya. 2003.

Berntein, D.K dan Tiegerman, E., The Nature of Language dan Its Disorders, Language and Communication in Children. 2003.

Budhiman, M., Autisme Dipandang dari Sudut Medis. Jakarta : POMDA Fpsi Universitas Indonesia. 2001.

Hamalik, O., Proses Belajar Mengajar. Jakarta : PT Bumi Aksara. 2004.

Hogan, B.N., Autism Treatment Center of America, The Son-Rise Program. USA : The Option Institute \& Fellowship. 2001.

Jordan, R. dan Powell, S., Autism with Severe Learning Difficulties. England : A Condor Book Son Venir Press. 2002.

Jordan, R. dan Powell, S., Understanding and Teaching Children with Autism. England : John wiley and Sons Ltd, Beffin Lane. 2002.

Kvale, S., Interviews An Introduction to Qualitative Research Interviewing. London : SAGE Publications, International and Professional Publisher. 1996. 


\section{"Ceria”}

Jurnal Pendidikan Anak Usia Dini

ISSN 2301-9905

Volume 10, No. 1, Juli 2019

Fakultas Keguruan dan Ilmu Pendidikan- Universitas Muhammadiyah Tangerang

Leaf, R. and McEachin, J., A Work in Progrees Behavior Management Strategies and A Curriculum for Intensive Behavioral Treatment of Autism. New York : DRL Books LLC. 1994.

Lovaas, O.I., Teaching Developmentally Disabled Children, The Me Book. United State of America : Pro-ED. 1981.

Maurice, C., Behavioral Intervention for Children with Autism A manual for Parent's Young and Professionals. Texas : Austin. 1996.

Nakita., Menangani Anak Autis. Jakarta. 2002.

Paul, R.. Interventions to improve communicationin autism. Child Adolescent Psychiatric Clinics of North America, 17, (2008), 835-856. DOI: 10.1016/j.chc.2008.06.011.

Rescorla, L. (1989). The language development survey: a screening tool for delayed language in toddlers. Journal of Speech and Hearing Disorders, 54, (1989), 587599. Diperoleh dari news.brynmawr. edu/files/2012.

Sussman, S., More Than Words, Helping Parent Promote Communication and Sosial Skills In Children with Sutism Spectrum Disorder, The Hanen Centre, Toronto, Ontario, Canada. 1999.

Tanjung, N.I. \& Siregar, E., Kiat Meningkatkan Spontanitas Penyandang Autisme dalam Berkomunikasi, Cara Berkomunikasi Melalui Pertukaran Gambar (PECS), Impleeintasi 108. 2000. 